\title{
A ATUAÇÃO DO MOVIMENTO FEMINISTA NO LEGISLATIVO FEDERAL: CASO DA LEI MARIA DA PENHA ${ }^{1}$
}

Renata Rodrigues Carone

é mestre em Ciência Política pela Universidade de Campinas. Campinas, SP, Brasil. E doutoranda

do Departamento de Estudos de Gênero da Universidade Estadual de Lisboa. Lisboa, Portugal.

E-mail: rercarone@gmail.com

Orcid: 0000-0003-4960-8167

http://dx.doi.org/10.1590/0102-181216/105

\section{Introdução}

Este artigo pretende explorar os efeitos da atuação do movimento feminista no Legislativo federal. Trata-se do caso de um Consórcio de ONGs feministas que atuou no Congresso Nacional para aprovar a Lei Maria da Penha². Assim denominada, a Lei 11.340/2006 dispõe sobre mecanismos para coibir a violência doméstica e familiar contra a mulher e, até sua aprovação, a questão era tratada pela Lei dos Juizados Especiais Criminais (Lei 9.099/95). O Consórcio ${ }^{3}$, composto por uma coalizão de ONGs feministas, juntamente com acadêmicas e juristas, tinha uma visão crítica sobre a aplicação da Lei 9.099/95 nos casos de

1 Este texto foi desenvolvido a partir da minha pesquisa de mestrado (Carone, 2017). Agradeço aos comentários às versões anteriores feitos por Luciana Tatagiba, Rebecca Abers, Wagner Romão, Monika Dowbor e Euzeneia Carlos.

2 A escolha do nome dessa lei serviu como uma reparação simbólica à Maria da Penha Maia Fernandes, que vivenciou um caso de violência doméstica conhecido nacionalmente (Calazans e Cortes, 2011).

3 As organizações não governamentais que compõem o consórcio e suas integrantes são: Cepia (Leila Linhares Barsted), Themis (Carmen Hein de Campos), Cladem (Silvia Pimentel), Cfemea (Iáris Ramalho Cortes), Advocaci (Beatriz Galli) e Agende (Elizabeth Garcez). Participaram também Rosana Alcântara, Rosane Reis Lavigne e Ela Wiecko de Castilho (Calazans e Cortes, 2011). 
violência doméstica e seu principal objetivo era criar uma solução legislativa mais adequada ao problema. A proposição que deu origem a Lei Maria da Penha foi apresentada pelo Executivo durante o governo Lula (2003-2006) e o Consórcio atuou de forma estratégica desde a inserção do tema na agenda até a definição do conteúdo legislativo que deveria ser aprovado no Congresso.

Segundo Andrews e Edwards (2004), muitos pesquisadores de movimentos sociais argumentam que é na fase de formação da agenda que as organizações têm maiores chances de influência nos processos políticos. Elas chamam atenção para determinada questão por meio de manifestações, campanhas educativas e lobbying, trazendo o senso da urgência em torno da reivindicação pretendida. Pesquisas recentes têm observado a atuação dos movimentos sociais em outras fases, como na elaboração e implementação das políticas públicas (Abers, Serafim e Tatagiba, 2014; Abers 182 e Tatagiba, 2014; Dowbor, 2012; Gutierres, 2015; Tatagiba e Teixeira, 2016; Teixeira, Tatagiba e Blikstad, 2015), no entanto, não existe uma agenda de pesquisa consolidada sobre sua atuação no parlamento.

Ainda que seja conhecida a contribuição dos movimentos sociais junto a partidos políticos para que leis importantes fossem aprovadas em vários setores de políticas públicas, no âmbito dos estudos legislativos, bem como na literatura de movimentos sociais, sabe-se muito pouco sobre sua atuação no Legislativo federal (Abers, Serafim e Tatagiba, 2014; Santos, 2014). Encontramos, todavia, casos empíricos reconhecendo que, pelo menos desde a Constituinte, movimentos sociais têm atuado na arena legislativa com o objetivo de levar suas demandas ao Congresso. Essa atuação ocorre por meio das emendas populares (Brandão, 2011; Lin, 2010); através da iniciativa popular de lei (Paz, 1996; Lin, 2010) e da Comissão de Legislação Participativa (Lin, 2010; Coelho, 2013); por meio da política de proximidade ou 
lobby (Abers, Serafim e Tatagiba, 2014; Dowbor, 2012); como grupo de pressão (Carvalho e Taglialegna, 2006); e nas comunidades de políticas (Pereira, Vasselai e Silva, 2012). Na esfera do movimento feminista, os achados são anteriores à Constituinte, localizados na chamada "primeira onda" (Matos, 2014), que se estende da virada do século XIX para o século XX, até 1932. Já nesse período, o movimento sufragista liderado por Bertha Lutz mobilizava repertórios voltados para a atuação no Congresso pelo direito ao voto feminino no Brasil (Alves, 1980; Hahner, 2003; Saffioti, 2013). Outros registros indicam que, na década de 1970, uma parte do movimento também atuava junto ao Legislativo por meio da apresentação de sucessivas propostas para alterar leis que reforçavam a desigualdade de gênero (Pitanguy, 1985; Barsted, 1994). Por fim, o acúmulo de pesquisas tem provado que os movimentos sociais não podem ser vistos como um elemento outsider no contexto institucional ${ }^{4}$; neste trabalho reafirmamos essa proposição, trazendo contribuições sobre os efeitos da atuação do movimento feminista ao longo da produção de uma política pública.

Em termos dos marcos conceituais e passos metodológicos adotados na pesquisa, ao falar do repertório de ação do Consórcio, estamos nos referindo a um conceito aplicado por Abers, Serafim e Tatagiba (2014) a partir de uma adaptação de repertoire of contention, criado por Charles Tilly. As autoras adaptaram esse conceito, concebido originalmente para o estudo dos movimentos sociais sob a chave das dinâmicas contenciosas, para um conceito que abarque relações que envolvam também dinâmicas colaborativas entre atores no Estado e na sociedade.

Para explorar a atuação do movimento feminista no Legislativo federal adotamos os conceitos de Kingdon (1995

\footnotetext{
${ }^{4}$ No que tange ao movimento feminista é importante mencionar também o mais recente trabalho de Biroli (2018).
} 
apud Capella e Brasil, 2015), para nos referirmos ao processo de formação da agenda, e Amenta et al. (2010) para tratar da produção do conteúdo da Lei Maria da Penha. O processo de formação da agenda, ou agenda setting, é aquele pelo qual as ideias competem para ganhar a atenção da mídia, da opinião pública e dos altos escalões governamentais. Em dado momento, uma lista de temas ou problemas torna-se alvo de atenção tanto por parte das autoridades governamentais quanto de pessoas estreitamente associadas às autoridades, integrando, assim, a agenda governamental. Quando a lista de assuntos dessa agenda é encaminhada para deliberação, ela passa a integrar a agenda de decisões (Kingdon, 1995); e uma política pública só tem início se o tema em debate evolui da agenda do governo para a agenda de decisões.

No artigo de Amenta et al. (2010), os efeitos da atuação legislativa do movimento são avaliados por meio da divisão 184 do momento da criação da lei em quatro processos: a) formação da agenda; b) conteúdo legislativo; c) votação e d) implementação ${ }^{5}$. Entretanto, para explorar a atuação do Consórcio no momento da produção do conteúdo legislativo, este trabalho não oferece um instrumental analítico, por isso, complementamos a análise com a proposta de Zampieri (2013). O autor observa as ações de defesa de interesses dos grupos de pressão nas Comissões Parlamentares em três momentos decisórios: definição da relatoria, formulação do parecer do relator e definição do posicionamento da comissão. A partir desses referenciais, analisamos o caso aqui exposto.

As principais fontes de dados utilizadas no trabalho foram encontradas nos portais da Câmara dos Deputados

\footnotetext{
${ }^{5}$ Existem autoras que reconhecem a participação do Consórcio de ONGs feministas no processo de implementação da Lei Maria da Penha (Calazans e Cortes, 2011; Maciel, 2011). No entanto, ao delimitar nosso interesse pela produção da política com foco no Legislativo federal, não tratamos da fase de implementação.
} 
(www2.camara.leg.br) e Senado Federal (www12.senado. leg.br). Na primeira casa legislativa, as informações foram extraídas a partir do mecanismo de busca disponível em "Proposições". Ao localizar o Projeto de Lei 4.559/20046, tivemos acesso à sua "ficha de tramitação", na qual estão os andamentos do processo legislativo desde a apresentação da proposição, passando pelas reuniões em comissões, pareceres dos relatores, substitutivos ${ }^{7}$, votos em separado ${ }^{8}$ etc. As reuniões e seminários ocorridos na Câmara estão disponíveis no formato de arquivo sonoro e as discussões ocorridas em plenário estão transcritas no "Diário Oficial" da casa.

No Senado, as informações foram extraídas pelo mecanismo de busca disponível em "Pesquisa de matérias". Também foi analisada a "ficha de tramitação" do Projeto de Lei da Câmara 37/2006; ela disponibiliza as comissões que analisaram a proposição, o parecer da relatora, a redação final do projeto etc. Com relação às reuniões realizadas nas comissões do Senado, não encontramos arquivo sonoro, porém localizamos a transcrição da reunião que nos interessava no mecanismo de busca "Comissões", posteriormente selecionando a Comissão desejada e a data do evento e acessando, por fim, as notas taquigráficas. No mecanismo de busca "Pronunciamentos" utilizamos as palavras-chave "violência doméstica" e delimitamos pelo período em que o projeto tramitou no Senado para encontrar discursos parlamentares relativos à matéria.

\footnotetext{
${ }^{6}$ A Lei Maria da Penha foi inicialmente proposta pelo Executivo durante o governo Lula (2003-2006) como Projeto de Lei 4.559/2004. Depois de tramitar na Câmara dos Deputados, o projeto chega ao Senado Federal como Projeto de Lei da Câmara 37/2006.

7 Substitutivo é uma espécie de emenda que altera, substancial ou formalmente, a proposição legislativa inicial em seu conjunto. Disponível em: <goo.gl/RGTLCK〉. Acesso em: 30 nov. 2016.

${ }^{8}$ Voto em separado é o voto de parlamentar que diverge do parecer dado pelo relator de determinada matéria. Disponível em: <goo.gl/hTN9kk>. Acesso em: 30 nov. 2016.
} 
Acrescentamos aos dados legislativos as cinco entrevistas realizadas com integrantes do Consórcio de ONGs e as duas realizadas com representantes do Legislativo, um assessor parlamentar e uma deputada que foi relatora do projeto na Câmara dos Deputados (CD $)^{9}$. Com exceção da entrevista da deputada Jandira Feghali ( $\left.\mathrm{PCdoB}^{10}-\mathrm{RJ}\right)$, que foi realizada por $e$-mail, todas foram presenciais e sob confidencialidade, sendo identificadas por números ao longo do texto ${ }^{11}$. O anteprojeto de lei produzido pelo Consórcio e entregue à Secretaria Especial de Política para as Mulheres ${ }^{12}$ (SPM) foi obtido mediante integrantes do grupo, e o relatório final do Convênio $^{13}$ realizado entre a SPM e o Centro Feminista de Estudos e Assessoria (CFEMEA) foi obtido através do e-SIC (Sistema Eletrônico do Serviço de Informação ao Cidadão) pela Lei de Acesso à Informação (LAI). Demais informações sobre as entrevistas, o roteiro utilizado e os documentos aqui citados podem ser encontrados na pesquisa de mestrado (Carone, 2017).

A metodologia de análise dos dados tem como ponto de partida a tramitação do projeto nas Casas Legislativas. Vale lembrar que o processo legislativo é fragmentado em múltiplos estágios decisórios, ou seja, não se trata de um jogo de rodada única. Nesse sentido, acompanhar a atuação

\footnotetext{
9 Para selecionar o universo de pessoas entrevistadas, seguimos as indicações apontadas por Calazans e Cortes (2011) sobre quais eram as organizações e as respectivas integrantes envolvidas no Consórcio de ONGs feministas. No caso dos representantes do Legislativo, selecionamos a deputada que mais se destacou na fala das integrantes envolvidas no Consórcio, bem como o assessor parlamentar também citado.

10 Partido Comunista do Brasil.

11 As entrevistas presenciais ocorreram entre os meses fevereiro e maio de 2016; foram gravadas e transcritas, com duração média de uma hora.

12 A SPM foi criada no governo Lula, por meio de uma medida provisória, posteriormente convertida em lei.

13 Trata-se do convênio 023/2003, realizado entre o Cfemea e a SPM, cujo objetivo principal era produzir um anteprojeto de lei sobre violência doméstica contra a mulher. O Cfemea foi uma das organizações não governamentais envolvidas no Consórcio.
} 
de uma organização na arena legislativa implica em entender o aspecto processual do funcionamento legislativo. Ao observar as fichas de tramitação e o desenrolar do processo, os repertórios de ação do Consórcio eram identificados e os substitutivos de cada Comissão Parlamentar eram comparados para verificar as alterações realizadas nos artigos do projeto de lei. Esse trabalho foi também subsidiado pelas informações obtidas nas entrevistas e no material produzido por integrantes do Consórcio (Barsted, 2011; Calazans e Cortes, 2011; Lavigne, 2011). Ao final, em termos da atuação do Consórcio no caso da Lei Maria da Penha, consideramos que a ação dessas organizações produziu efeitos importantes sobre a produção da política pública, o que será argumentado nos próximos tópicos.

O texto está estruturado em três seções. Em primeiro lugar, vamos tratar da formação do Consórcio e do debate que há por trás da Lei Maria da Penha. Em seguida, fazemos uma discussão sobre os dois processos em que reconhecemos a atuação do grupo no caso: formação da agenda e produção do conteúdo legislativo. Por último, apresentamos as considerações finais.

\section{A formação do Consórcio de ONGs feministas e a discussão por trás da Lei Maria da Penha}

Antes da Lei Maria da Penha ser aprovada, os crimes de violência doméstica contra a mulher eram tratados pela Lei 9.099/95, que definia como delito de menor potencial ofensivo os crimes previstos no Código Penal cuja pena máxima não excedesse dois anos de reclusão. Nessa categoria estavam também tipos penais comumente praticados contra as mulheres, como lesão corporal leve e ameaça, considerados como delitos de menor importância. A lei previa que eles fossem tratados por mecanismos judiciais mais simplificados, como a conciliação, destinando o encarceramento aos crimes considerados graves. Como consequência, a maioria 
dos casos de violência doméstica (cerca de 90\%) terminava em arquivamento nas audiências de conciliação em nome da harmonia familiar, sem que as mulheres encontrassem uma resposta efetiva do poder público sobre a questão (Calazans e Cortes, 2011). Nos poucos casos em que ocorria a punição do agressor, sua condenação geralmente consistia na entrega de cestas básicas a entidades filantrópicas. Para o movimento feminista, ainda que existissem pontos positivos trazidos pela Lei 9.099/95, nos casos de violência doméstica contra a mulher a sua aplicação apresentava absoluta inadequação funcional $^{14}$ (Lavigne, 2011).

A própria formação do Consórcio foi motivada, principalmente, pelos debates dos aspectos críticos da Lei dos Juizados Especiais Criminais (Lei 9.099/95) e o quanto essa norma vinha contribuindo para a impunidade dos crimes de violência doméstica contra as mulheres (Barsted, 2007). Além disso, essa legislação estava em desacordo com a Convenção de Belém do Pará, ratificada pelo governo brasileiro, que considera a violência contra a mulher uma violação de direitos humanos, ou seja, um crime de grande gravidade em oposição à ideia de delito de menor potencial ofensivo. Nesse contexto, o principal ponto defendido pelo Consórcio era a não aplicação da Lei 9.099/95 sobre os crimes de violência doméstica, defendido como uma cláusula pétrea pelas organizações feministas (Calazans e Cortes, 2011). Outro ponto importante é o fato de que os Juizados Especiais Criminais tratavam somente do delito penal, mas para a mulher vítima de violência doméstica resolver outras questões (separação, pensão, guarda de filhos) era preciso ingressar com outro processo na vara de família (Brasil,

\footnotetext{
14 Para outra visão da Lei 9.099/95, ver Montenegro (2015). A autora concorda que a lei apresenta graves problemas para tratar dos casos de violência doméstica, mas reconhece nela alternativas para além do discurso punitivo, proporcionando o diálogo entre as partes. Antes dessa lei, as denúncias de agressões físicas ou morais não saíam das delegacias e não chegavam a gerar nenhum procedimento formal, pois eram resolvidas amigavelmente entre o comissário de polícia e as partes.
} 
2010). Em vista disso, o Consórcio defendia a criação das Varas Especializadas de Violência Doméstica, com juízo cível e criminal, congregando diversas competências em um mesmo Juizado para dar celeridade às diferentes demandas (cíveis, penais e administrativas) das mulheres em situação de violência.

O Consórcio envolveu uma coalizão de seis organizações não governamentais feministas $\left(\right.$ Cepia $^{15}$, CFEMEA $^{16}$, Cladem $^{17}$, Themis, Advocaci ${ }^{18}$ e Agende $^{19}$ ) que em 2001 se articulou para produzir uma solução legislativa para o problema da violência doméstica contra as mulheres. Ao longo de 2002, esse grupo passou a ser denominado de Consórcio de ONGs (Barsted, 2007) ou Consórcio de ONGs feministas (Calazans e Cortes, 2011). Tratam-se de organizações que, em sua maioria, moldaram-se para atuar na arena legislativa desde a sua fundação. Suas integrantes tinham formação jurídica e eram ligadas historicamente ao movimento feminista, mas também ao Estado, pela atuação de algumas delas no Conselho Nacional dos Direitos da Mulher (CNDM) e do trabalho na Constituinte.

Por outro lado, os posicionamentos divergentes em relação às feministas eram representados, principalmente, pelos representantes do Fórum Nacional dos Juizados Especiais (Fonaje), que defendiam a manutenção da legislação vigente. Eles questionavam a atribuição exclusiva da mulher ao papel de sujeito passivo de relações violentas e a premissa que exclui a possibilidade de que os homens também ocupem esse papel. Nessa visão, um dos argumentos utilizados pelos representantes do Fórum Nacional de Juizados Especiais (Fonaje) era que, entre pares que

\footnotetext{
15 Cidadania, Estudo, Pesquisa, Informação e Ação (Cepia).

16 Centro Feminista de Estudos e Assessoria (CFEMEA).

17 Comitê da América Latina e Caribe para a Defesa dos Direitos das Mulheres (Cladem).

18 Advocacia Cidadã pelos Direitos Humanos (Advocaci).

19 Ações em Gênero, Cidadania e Desenvolvimento (Agende).
} 
mantêm relações de afetividade, a especificidade de uma lei para as mulheres feria "o princípio da igualdade proposto pela Constituição Federal de 1988” (Romeiro, 2007, p. 89). Além disso, duas outras críticas são apontadas pelos operadores jurídicos. Uma delas recai sobre a não aplicação da Lei 9.099/95 e a penalização, via encarceramento, para os delitos de violência doméstica contra a mulher, deixando de lado a perspectiva da conciliação. Outro ponto está relacionado à interferência da lei na organização jurídica de estados e municípios. Isso porque o artigo 33 da Lei Maria da Penha prevê que as Varas Criminais julguem os crimes de violência doméstica contra a mulher, acumulando competências cível e criminal, enquanto não sejam estruturados os Juizados de Violência Doméstica e Familiar. Segundo relatório do Fonaje é "absolutamente inconstitucional qualquer interferência sobre a organização judiciária dos Estados e do Distrito Federal” (Romeiro, 2009, p. 67).

As divergências entre o Consórcio e os representantes do Fonaje perpassam todo o processo de produção da Lei Maria da Penha, desde o Grupo de Trabalho Interministerial ${ }^{20}$ (GTI) até a discussão do projeto no Senado Federal (SF). No GTI, os próprios operadores jurídicos defenderam esses pontos na discussão com representantes do movimento feminista e demais atores governamentais. Ao longo do processo legislativo, os posicionamentos dos dois grupos se refletiram nas visões dos parlamentares que reproduziram muitos dos questionamentos trazidos tanto pelos operadores jurídicos quanto pelo Consórcio de ONGs feministas. Assim, iremos abordar no próximo tópico a atuação do Consórcio sobre

\footnotetext{
${ }^{20}$ Por meio do decreto presidencial n 5.030, de 31 de março de 2004, o Grupo de Trabalho Interministerial foi instituído para elaborar proposta legislativa com o intuito de coibir a violência doméstica, sob coordenação da Secretaria Especial de Política para as Mulheres (SPM). Disponível em: <goo.gl/GCGGYS >. Acesso em: 15 jun. 2016.
} 
a fase inicial da produção da política, trazendo o tema da violência doméstica para ser deliberado na arena legislativa.

\section{A atuação do Consórcio na formação da agenda}

Olhando retrospectivamente sobre o tema da violência contra as mulheres na agenda pública brasileira, Santos (2010) afirma que no início dos anos 1980 a violência doméstica teve um destaque central nos discursos e mobilizações feministas. Nessa época, chamavam atenção os casos de assassinatos de mulheres e a absolvição dos assassinos pelos tribunais, com base na tese da legítima defesa da honra. A grande repercussão na imprensa do assassinato de mulheres de classe média por seus maridos deflagrou a entrada desse tema na agenda pública (Sorj e Monteiro, 1985 apud Moraes e Sorj, 2009). Em 1976, um caso emblemático foi o de Doca Street, que assassinou sua companheira Ângela Diniz e, mesmo sendo réu confesso, foi absolvido pelo Tribunal do Júri alegando a tese da legítima defesa da honra. Os argumentos utilizados no julgamento pela defesa do acusado retratavam Ângela como uma mulher que bebia muito, de personalidade neurótica e com perturbações comportamentais, traduzidas pela sua agressividade excessiva (Lins e Silva, 1991 apud Blay, 2008). Como explica Blay (2008), a estratégia dos advogados de defesa de Doca Street era criar uma polarização entre o seu comportamento e o de Ângela, de forma que se julgasse uma imagem social e sua representação, ao invés do crime. A sentença da justiça sobre esse caso "provocou uma das primeiras grandes campanhas públicas das feministas no Brasil e, com certeza, foi grandemente responsável pela condenação do assassino em um segundo julgamento" (Pinto, 2003, p. 80).

Ao longo do tempo, o Estado respondeu algumas das demandas feministas que se relacionam com essa temática através da criação dos Conselhos Estaduais da Condição Feminina, Conselho Nacional dos Direitos da Mulher, 
Delegacias de Defesa da Mulher e a criação das agências estatais, com destaque para a Secretaria Especial de Política para as Mulheres (SPM). No entanto, em 2001, um acontecimento importante tornou pública a necessidade de o governo repensar a forma como a violência doméstica estava sendo tratada pelo Estado (Sarmento, 2013). Esse acontecimento está relacionado ao caso de Maria da Penha Maia Fernandes, vítima de sucessivos atos de violência física e psicológica por parte do seu marido, que tentou assassiná-la em duas ocasiões, em 1983. Desde então, não haviam sido tomadas medidas efetivas pela justiça brasileira para julgar e punir o agressor, apesar das acusações apresentadas.

Em 1998, esse caso foi levado pela própria vítima à Comissão Interamericana de Direitos Humanos (CIDH), da Organização dos Estados Americanos (OEA), apoiada por ONGs atuantes na temática. Em 2001, a Comissão responsabilizou o Estado brasileiro por tolerância em relação 192 à violência doméstica contra as mulheres, inaugurando jurisprudência internacional nessa matéria. Ao final, a decisão favorável da Comissão Interamericana dos Direitos Humanos (CIDH) impulsionou mobilização nacional sobre o tema (Maciel, 2011).

Em 2003, a recomendação da Cedaw (Convention on the Elimination of All Forms of Discrimination Against Women $)^{21}$ para que o governo brasileiro elaborasse uma legislação sobre violência doméstica (Santos, 2010), aliada à mobilização do movimento, tornou o problema ainda mais evidente. Durante as últimas décadas, o governo reconhecia a pressão do movimento feminista para que o Estado

\footnotetext{
${ }^{21}$ A sigla Cedaw foi traduzida em português como Convenção Sobre a Eliminação de Todas as Formas de Discriminação Contra a Mulher. Essa convenção foi aprovada pela Organização das Nações Unidas (ONU), em 1979, e ratificada pelo Brasil, em 1984. Ela define a violência contra a mulher como um ato de discriminação, pois prejudica o pleno exercício dos seus direitos fundamentais.
} 
assumisse o seu papel no enfrentamento dessa questão (Brasil, 2006).

Diante desse cenário, e com a criação da Secretaria Especial de Política para as Mulheres (SPM) no governo Lula, em 2003, a situação pareceu favorável à ação do Consórcio de ONGs feministas. Para Santos (2010), a criação da agência permitiu a possibilidade de alianças entre governo e as ONGs feministas. Pinheiro (2015) observa também que, por meio da SPM, houve a inserção de ativistas no governo, pela ocupação de cargos na burocracia estatal. Segundo a autora, pelo fato dessas burocratas estarem num governo que compartilhava, de alguma forma, os projetos defendidos pelas feministas na sociedade civil, foi possível fazer avanços na agenda de temas como a violência, por exemplo.

A SPM era vinculada ao gabinete presidencial e sua liderança tinha status de ministro(a), o que representava um avanço em relação às agências anteriormente criadas em nível federal (Bohn, 2010). Seu objetivo era desenvolver ações conjuntas com os demais ministérios e secretarias, incluindo as especificidades das mulheres nas políticas públicas executadas pelo governo federal. A percepção de uma das integrantes do Consórcio era de um ministério recente, com estrutura pequena, mas composto de muitas burocratas vinculadas ao movimento feminista (entrevista 4). É citado o nome da assessora parlamentar da SPM à época, Regina Adami ${ }^{22}$, que vinha do movimento feminista, como um ponto focal importante. Em vista disso, havia a ideia de se construir em parceria uma legislação para tratar da violência doméstica.

Com a percepção política de que havia uma janela de oportunidades aberta, o Consórcio compartilhou sua visão

22 O nome da assessora parlamentar foi citado na pesquisa de mestrado (Carone, 2017) como Regina Dantas, mas o nome correto é Regina Adami. 
sobre o problema e apontou alternativas, encontrando interlocutores tanto na arena legislativa quanto na do Executivo. Segundo Kingdon (1995), uma janela aberta para políticas públicas constitui uma oportunidade para que os atores chamem atenção para determinados problemas ou para que ofereçam soluções para certa questão. De fato, segundo a ministra da SPM à época , a agenda se iniciou com a articulação do Consórcio, que apresentou sua minuta de anteprojeto tanto à bancada feminina quanto ao Executivo ${ }^{23}$. Entre 2001 e 2003 houve o processo de elaboração de uma proposta legislativa pelo grupo que durou, pelo menos, dois anos. Os registros indicam que, em novembro de 2003, a minuta do Consórcio foi apresentada à bancada feminina da Câmara dos Deputados, num seminário sobre violência doméstica ${ }^{24}$.

O Seminário foi realizado pela Comissão de Segurança 194 Pública e Combate ao Crime Organizado (CSPCCO) da Câmara, através do requerimento da deputada Iriny Lopes (PT-ES). A deputada explica que foram constituídos, dentro da Comissão de Segurança Pública da Câmara dos Deputados, alguns subgrupos de trabalho e um deles, do qual ela era relatora, tratava da violência. Segundo a deputada, a expectativa do evento era trazer ideias e proposições que ajudassem os parlamentares na aprovação das leis sobre violência doméstica contra as mulheres. Em resumo, a minuta de anteprojeto apresentada pelo Consórcio nesse Seminário continha as seguintes propostas:

\footnotetext{
23 Fala da ministra Nilcéa Freire, no Seminário Violência contra a mulher: um ponto final, realizado para debater o PL no 4.559, de 2004, que cria mecanismos para coibir a violência doméstica e familiar contra a mulher. Ocorrido em 16 de agosto de 2005. Disponível em: <goo.gl/SIFcX5>. Acesso em: 10 jun. 2016.

${ }^{24} \mathrm{O}$ arquivo sonoro do seminário em que o Consórcio apresenta a minuta à bancada feminina da Câmara está disponível em: <goo.gl/jEvq3x> (manhã) <goo.gl/ dH6FFc > (tarde). Acesso em: 10 jun. 2016.
} 
a) conceituação da violência doméstica contra a mulher com base na Convenção de Belém do Pará, incluindo a violência patrimonial e moral;

b) criação de uma Política Nacional de combate à violência contra a mulher;

c) medidas de proteção e prevenção às vítimas;

d) medidas cautelares referentes aos agressores;

e) criação de serviços públicos de atendimento multidisciplinar;

f) assistência jurídica gratuita para as mulheres;

g) criação de um Juízo Único com competência cível e criminal através de Varas Especializadas para julgar os casos de violência doméstica contra as mulheres e outros relacionados;

h) não aplicação da Lei 9.099/1995 - Juizados Especiais Criminais - nos casos de violência doméstica contra as mulheres. (Calazans e Cortes, 2011, p. 44).

É interessante notar a participação do Consórcio nesse seminário com a pauta de apresentar sua proposta legislativa, considerando que a presença de membros da sociedade civil como expositores nesses eventos depende de convite por parte dos parlamentares. Ao questionarmos as entrevistadas sobre como se deu essa oportunidade, uma delas respondeu: "a gente já estava dentro" (entrevista 3). Outra complementou que as organizações feministas, como o CFEMEA, são sempre chamadas pela bancada feminina para participar das pautas do Congresso relacionadas às mulheres (entrevista 4).

No próprio seminário, as parlamentares discutiram sobre formas de apresentação da proposta legislativa do Consórcio ao Congresso. Ao final, Calazans e Cortes (2011) relatam que se chegou ao consenso de que a proposta deveria ser feita pelo Executivo. O principal motivo apontado pelas autoras é o fato de que o projeto incluía 
a criação de despesas cuja competência cabe ao Executivo - como, por exemplo, a criação de Varas Especializadas para julgar os casos de violência doméstica. Desse modo, a Secretaria Especial de Política para as Mulheres (SPM) se engajou na questão "prontificando-se a dar andamento ao projeto no menor espaço de tempo possível" (Calazans e Cortes, 2011, p. 45).

A partir de dezembro de 2003, uma das organizações integrantes do Consórcio passa a receber um financiamento da SPM, por meio de um convênio, cujo objetivo principal era a produção de um anteprojeto de lei sobre violência doméstica contra a mulher. Posteriormente, todo o material produzido através do convênio foi oficialmente entregue à SPM, em março de 2004. Esse material foi utilizado como subsídio nas discussões do Grupo de Trabalho Interministerial (GTI).

O GTI foi criado por iniciativa da então ministra Nilcéa 196 Freire (SPM) para elaborar o projeto de lei que cria mecanismos para coibir a violência doméstica e familiar contra a mulher. Foram envolvidos nessa discussão representantes de diversos ministérios, além de grupos da sociedade civil como o Consórcio de ONGs feministas; Articulação de Mulheres Brasileiras (AMB); Rede Nacional Feminista de Saúde, Direitos Sexuais e Direitos Reprodutivos e Fórum Nacional de Juizados Especiais (Fonaje).

O Consórcio se envolveu nas discussões que acabaram por definir o conteúdo do projeto que seria apresentado pelo Executivo, e a sua proposta serviu de insumo para o produto final do GTI, apresentado ao Congresso por meio do Projeto de Lei 4.559/2004. Entretanto, em alguns pontos importantes da discussão, o lobby do Fórum Nacional de Juizados Especiais (Fonaje) saiu vitorioso, por isso, a estratégia das ONGs feministas foi reverter esses pontos na discussão no Legislativo. É importante dizer que antes do projeto de lei chegar ao Congresso, tanto o Consórcio quanto o Conselho Nacional 
dos Direitos da Mulher receberam a versão final do texto e a sinalização da SPM foi que "as discussões e a negociação dos pontos divergentes poderiam ser feitas no âmbito do Legislativo" (Barsted, 2007, p. 133). Em suma, tudo indica que foi o Consórcio quem primeiramente propôs o anteprojeto de lei aos atores políticos, de forma a inserir o tema na agenda. Apresentamos a seguir uma tabela com a sequência dos fatos.

\section{Quadro 1}

\section{Cronologia da apresentação do PL 4.559/2004 ao Legislativo federal}

\begin{tabular}{|c|l|}
\hline Período & \multicolumn{1}{c|}{ Encaminhamento } \\
\hline 2001 & $\begin{array}{l}\text { Comissão Interamericana de Direitos Humanos (CIDH) analisa o } \\
\text { caso Maria da Penha e responsabiliza o governo brasileiro por tole- } \\
\text { rância estatal em relação à violência doméstica contra as mulheres. } \\
\text { Articulação do Consórcio de ONGs feministas para debater as- } \\
\text { pectos críticos da Lei 9.099/95. }\end{array}$ \\
\hline $2001-2003$ & $\begin{array}{l}\text { Ao longo de dois anos de reuniões e estudos, o Consórcio ela- } \\
\text { bora minuta de anteprojeto sobre violência doméstica contra a } \\
\text { mulher. A coordenação do grupo ficou sob responsabilidade do } \\
\text { CFEMEA, por estar sediado em Brasília e pela experiência da or- } \\
\text { ganização em advocacy no Legislativo e Executivo. }\end{array}$ \\
\hline 2003 & $\begin{array}{l}\text { Criação da Secretaria Especial de Políticas para as Mulheres (governo } \\
\text { Lula), vinculada à Presidência da República, com status ministerial. } \\
\text { Comitê Cedaw recomenda ao governo brasileiro a elaboração de } \\
\text { legislação sobre violência doméstica. }\end{array}$ \\
\hline Novembro de & $\begin{array}{l}\text { Consórcio apresenta minuta de anteprojeto de violência domés- } \\
\text { tica contra as mulheres em seminário realizado na Câmara dos } \\
\text { Deputados. }\end{array}$ \\
\hline $\begin{array}{c}\text { Dezembro } \\
\text { de } 2003 \text { a }\end{array}$ & $\begin{array}{l}\text { SPM e CFEMEA realizam um convênio cujo objetivo principal era } \\
\text { a produção de um anteprojeto de lei sobre violência doméstica } \\
\text { contra a mulher. }\end{array}$ \\
\hline 2004 & $\begin{array}{l}\text { Consórcio apresenta sua proposta legislativa à ministra da SPM. } \\
\text { Criação do Grupo de Trabalho Interministerial, sob coordenação } \\
\text { da SPM, cuja finalidade era elaborar proposta legislativa para coi- } \\
\text { bir a violência doméstica contra a mulher. O anteprojeto produzi- } \\
\text { do pelo Consórcio é o documento-base da discussão no GTI, em } \\
\text { que as organizações também participam. }\end{array}$ \\
\hline $\begin{array}{c}\text { Dezembro de } \\
2004\end{array}$ & $\begin{array}{l}\text { Executivo apresenta ao Congresso o Projeto de Lei 4.559/2004, que } \\
\text { cria mecanismos para coibir a violência doméstica e familiar contra } \\
\text { a mulher, nos termos do § 8 do artigo 226 da Constituição Federal. }\end{array}$ \\
\hline
\end{tabular}

Fonte: Elaboração própria 
Como já apontamos, a participação do Consórcio, tanto no seminário da Câmara quanto no Grupo de Trabalho Interministerial (GTI), depende de um convite por parte dos atores políticos, o que denota o trânsito dessas organizações junto ao Executivo e no parlamento. Além disso, tudo indica que as organizações do Consórcio integram uma comunidade de políticas (policy communities) sobre o tema. Segundo Kingdon (1995 apud Capella e Brasil, 2015), as comunidades de políticas são integradas por um conjunto de especialistas que atuam numa área comum e compartilham preocupações relacionadas à determinada política pública. Essas comunidades compostas por atores governamentais, assessores parlamentares, membros de consultorias, grupos de interesse etc. podem gerar ideias que se transformarão em políticas adotadas pelos tomadores de decisão.

O próprio convênio realizado entre SPM e CFEMEA também corrobora para esse entendimento, uma vez que a agência 198 estatal repassou recursos financeiros para uma das organizações integrantes do Consórcio, com o objetivo principal de que as organizações se dedicassem a produzir o anteprojeto de lei sobre violência doméstica e familiar contra a mulher. Tal anteprojeto, como já destacamos, é usado como subsídio para as discussões ocorridas no GTI. Sendo assim, quando a agenda chega ao Congresso como PL 4.559/04 ela já havia sido construída com base no que o grupo havia pautado, tanto no Legislativo quanto no Executivo. Os principais termos da discussão foram trazidos pelo Consórcio e eles giram em torno, principalmente, da não aplicação da Lei 9.099/95 e da criação dos Juizados de Violência Doméstica com competência cível e criminal. Sobre o primeiro ponto, a ministra Nilcéa Freire afirmou que o principal conflito ocorrido no GTI foi sobre a Lei 9.099/95 25 .

25 Fala da Ministra da SPM, Nilcéa Freire, na Audiência Pública realizada para debater o PL nº 4559, de 2004, que cria mecanismos para coibir a violência doméstica e familiar contra a mulher. Ocorrida em 26 de abril de 2005. Disponível em: <goo.gl/HO8Kil>. Acesso em: 10 jun. 2016. 
Nesse sentido, segundo Kingdon (1995), o Consórcio completou os pré-requisitos que fazem com que determinada condição seja vista como um problema e ascenda para a agenda de decisões. Nos termos do autor (apud Capella e Brasil, 2015), a agenda governamental é afetada por três fluxos - problemas, soluções e contexto político - e quando existe uma confluência entre os problemas e as soluções num contexto político favorável podem ocorrer mudanças nas políticas públicas. Na exposição de motivos ${ }^{26}$, apresentada pela ministra da SPM junto ao PL 4.559/04, observamos o reconhecimento do grupo no processo, trazendo a questão ao governo, informação também reforçada no próprio relatório institucional da agência estatal (Brasil, 2006). Em relação ao contexto político, destacamos a receptividade da SPM ao tema; e a articulação entre o Executivo, a bancada feminina do Congresso e as organizações do Consórcio (Brasil, 2006; Pinheiro, 2010; 2015).

No próximo tópico, será abordada a atuação do Consórcio sobre a produção da Lei Maria da Penha no Congresso.

\section{A atuação do Consórcio sobre o conteúdo legislativo da Lei Maria da Penha}

Ainda que, de modo geral, o projeto de lei apresentado pelo Executivo (PL 4.559/04) tenha incorporado grande parte das propostas apresentadas pelo Consórcio (Calazans e Cortes, 2011), a SPM cedeu ao lobby dos juízes. A Secretaria Especial de Política para as Mulheres (SPM) acolheu as objeções dos operadores jurídicos, mantendo os crimes de violência doméstica sob a égide da Lei 9.099/95, ainda que com algumas adaptações (Lavigne, 2011). Esses crimes continuariam a ser julgados, separadamente, pelos Juizados Especiais Criminais e os Juizados Especiais Cíveis enquanto

26 Disponível em: <goo.gl/phqJdb>. Acesso em: 5 out. 2016. 
não fossem criados os Juizados de Violência Doméstica e Familiar. Ambas as propostas colidiam com a visão defendida pelo Consórcio apresentada ao Executivo. Em suma, o projeto apresentado ao Congresso estava em desacordo com alguns pontos levantados pelo Consórcio e, em contrapartida, atendia aos anseios dos representantes dos Juizados Especiais Criminais, presentes nas discussões do Grupo de Trabalho Interministerial.

Na visão das representantes do Consórcio, era esperado que o texto apresentado pelo grupo fosse modificado no momento em que ele fosse discutido num grupo mais amplo e com a presença dos operadores jurídicos (entrevistas 3 e 4). O Consórcio tinha voz no Grupo de Trabalho Interministerial, mas enfrentava resistências e críticas ao documento apresentado. O texto final refletiu esses embates dando vantagem aos representantes do Fórum Nacional de Juizados Especiais (Fonaje), mas, ainda assim, as entrevista200 das acreditavam que a derrota no GTI poderia ser revertida no Legislativo, que é um campo onde o grupo sabe atuar (entrevista 1).

O PL 4.559/2004 tramitou ao longo do primeiro mandato do presidente Luiz Inácio Lula da Silva (2003-2006), e ao longo do período, a porcentagem de cadeiras da coalizão do governo era majoritária tanto na Câmara dos Deputados quanto no Senado Federal ${ }^{27}$. Nesse sentido, é importante relembrar que o Congresso é regido pelo princípio majoritário, ou seja, pela formação de maiorias que fornecem o número de votos necessários para a aprovação de determinada proposta legislativa (Junqueira, 2016). Além disso, os projetos de iniciativa do Executivo são preponderantes na produção legislativa, sendo raramente derrotados, o que se comprova pelas suas altas taxas de sucesso e dominância na produção das leis (Figueiredo e Limongi, 1999).

27 Freitas (2016, p. 148-149). 
Ademais, como nos explica Freitas (2016), quando o Executivo envia um projeto de lei ao Congresso apenas se inicia o processo legislativo. A autora argumenta que no interior das Comissões Parlamentares novas informações serão produzidas sobre a matéria e os parlamentares apresentarão os pontos divergentes em relação à proposta original do Executivo. Adicionalmente, a sociedade civil se manifestará sobre a temática e então começa um intenso processo de barganha. Em resumo, quando um projeto dá entrada no Congresso, "a matéria se torna pública e oposição, coalizão e a sociedade civil entram no debate" (p. 46). Sendo assim, se é inegável que o Executivo ocupa um papel centralizador no processo decisório brasileiro, isso não deve ser visto como um obstáculo "à capacidade do Legislativo de alterar as propostas que partem do Poder Executivo" (p. 10). Os achados de pesquisa da autora indicam que os projetos de iniciativa do Executivo são alterados pelo Legislativo e que o processo de alterações é coordenado pela coalizão no interior da arena legislativa. Essas alterações ocorrem, principalmente, nas Comissões Parlamentares e o relator, normalmente um membro do partido da coalizão, representa esse papel de coordenador de preferências.

Nas comissões, o relator é o parlamentar designado para elaborar parecer sobre matéria de competência do colegiado podendo emendar ou mesmo alterar o projeto original $^{28}$. Se o parecer é aprovado pelo plenário da comissão, em todos os seus termos, transforma-se no parecer do colegiado, mas se forem sugeridas alterações com as quais o relator concorde, é atribuído um prazo até a reunião seguinte para a redação do novo texto. Por outro lado, se o voto do relator não for adotado pela comissão, a redação

\footnotetext{
28 A escolha dos relatores é atribuição do presidente da comissão, cujas demais funções incluem representar o colegiado, conduzir os trabalhos e resolver questões regimentais. A lista completa de funções está no artigo 41 do Regimento Interno da Câmara dos Deputados (Brasil, 2011).
} 
do parecer vencedor é feita pelo relator substituto ${ }^{29}$. Para Santos e Almeida (2005), além das funções regimentais pré-determinadas, o relator encarna a figura do agente informacional da comissão, cuja atribuição consiste na coleta e divulgação de informação sobre as consequências da proposta de política pública a ser analisada.

No que tange às comissões, Junqueira (2016) indica o sistema de comissões brasileiro como peça-chave do processo decisório. Ela retoma os achados da pesquisa de Freitas (2016), destacando a relevância da participação dos parlamentares na produção legislativa, que se concretiza no interior das comissões parlamentares por meio das alterações empreendidas por membros da coalizão. A autora advoga, em resumo, que as comissões servem à produção de informação sobre os projetos em discussão e à ação partidária.

Levando em conta esses achados de pesquisa, verificamos que no caso do Consórcio sua interação com a 202 arena legislativa se deu pelo ponto de acesso estratégico, com maiores chances de sucesso do ponto de vista institucional. A partir do momento em que o PL 4.559/2004 é apresentado pelo Executivo ao Congresso, muito da atuação do Consórcio ao longo da tramitação da matéria ocorreu dentro das comissões e em contato com a relatoras do projeto, tanto na Câmara dos Deputados quanto no Senado Federal $^{30}$. As organizações atuaram ao longo dos processos decisórios que ocorreram nas Comissões, mobilizando diversos repertórios com o intuito de defender alguns pontos essenciais sobre o conteúdo da lei que estava em discussão.

\footnotetext{
29 Essas disposições foram extraídas de Brasil (2011). No artigo 57 do Regimento Interno da Câmara dos Deputados (incisos XI e XII) estão previstas normas relativas ao trabalho do relator nas comissões.

30 Ao longo do processo legislativo, a proposição tramitou na Câmara dos Deputados em três comissões: Comissão de Seguridade Social e Família (CSSF), Comissão de Finanças e Tributação (CFT), Comissão de Constituição e Justiça e de Cidadania (CCJC); no Senado, o projeto tramitou na Comissão de Constituição, Justiça e Cidadania (CCJ).
} 
De acordo com a pesquisa de Carone (2017), tudo indica que a deputada Jandira Feghali (PCdoB-RJ), relatora na Comissão de Seguridade Social, foi quem mais fez alterações no projeto, coordenando esse processo enquanto representante do partido da coalizão majoritária. Os indícios que sustentam tal suspeita são: a) as audiências públicas ocorridas em diversos estados (no âmbito da Comissão de Seguridade Social) para debater o projeto de lei com o envolvimento do Consórcio, SPM e de alguns parlamentares importantes das comissões seguintes; b) a participação da SPM e demais relatores na própria tramitação do projeto nessa Comissão; c) o número total de artigos do substitutivo da Comissão (55 artigos), em comparação ao projeto apresentado pelo Executivo (47 artigos); e d) a participação da deputada Jandira Feghali nos processos decisórios relativos às Comissões de Constituição e Justiça e Cidadania (CCJC) da Câmara e à Comissão de Constituição e Justiça (CCJ) do Senado, para garantir que parte das mudanças realizadas em sua relatoria fosse mantida nas etapas seguintes. Na visão de Sarmento (2013), uma das personagens mais importantes para a aprovação da lei foi a deputada Jandira. Vale notar também que é na Comissão de Seguridade Social que o projeto é modificado com relação à não aplicação da Lei 9.099/95, e as integrantes do Consórcio são nominalmente citadas pela relatora por sua participação na reformulação do texto vindo do Executivo ${ }^{31}$. Nesse sentido, considera-se que a atuação do Consórcio incidiu não apenas na formação da agenda, mas também sobre o próprio conteúdo legislativo da Lei Maria da Penha. Isso é confirmado também por Nunes (2012), ao reconhecer que consta no texto da lei promulgada a maioria das reivindicações feitas pelo Consórcio:

31 Fala da Deputada Jandira Feghali no seminário Violência contra a mulher: um ponto final, realizado para debater o PL n⿳0 4559, de 2004, que cria mecanismos para coibir a violência doméstica e familiar contra a mulher; ocorrido em 16 de agosto de 2005. Disponível em: <goo.gl/SlFcX5>. Acesso em: 10 jun. 2016. Essa informação também é confirmada nas entrevistas (Carone, 2017, p. 97). 
Consta do texto da Lei no 11.340 , de 2006, a maioria das reivindicações feitas pelo Consórcio de ONGs ao longo do processo de elaboração e discussão do Projeto, a exemplo da definição da violência doméstica contra a mulher como uma questão de gênero (Art. $5^{\circ}$ ); a declaração de que essa violência constitui uma violação dos direitos humanos das mulheres em oposição à concepção anterior de delito de menor potencial ofensivo (Art. $6^{\circ}$ ), o afastamento da Lei no 9.099/95 desses casos (Art. 41); as medidas de assistência e prevenção, entre essas as medidas protetivas de urgência (Art. 22); e a determinação para a criação de Juizados de Violência Doméstica e Familiar contra a Mulher, com competência mista, cível e criminal (Art. 33) (Nunes, 2012, p. 76).

Amenta et al (2010) discutem em seu texto as consequências políticas da atuação dos movimentos sociais. 204 Segundo os pesquisadores, uma vez que os atores sociais não são os tomadores de decisão, as consequências de suas ações sobre os processos políticos não estão sob o seu controle, o que implica na dificuldade de se atribuir ao movimento determinado resultado na política, ou seja, o problema de se aferir efeito causal nos termos apontados por Tatagiba e Teixeira (2016). A literatura encontra certa dificuldade em reconhecer a efetividade da ação dos movimentos sobre os processos políticos e, em vista disso, os autores sugerem algumas proposições metodológicas que adotaremos aqui.

Segundo Amenta et al (2010), para uma argumentação convincente sobre a incidência de um movimento social na produção da política é preciso demonstrar que os movimentos sociais impactaram um ou mais dos pontos a seguir: planos e agendas de líderes políticos; conteúdo das propostas elaboradas por representantes do Executivo ou Legislativo; votos de representantes-chave para a aprovação da lei; e velocidade ou a natureza da implementação 
do projeto aprovado. Em relação a esses pontos, consideramos que a atuação do Consórcio teve impacto na agenda governamental e no conteúdo do projeto de lei apresentado pelo Executivo, bem como na versão do texto aprimorada na arena legislativa.

É importante dizer que, por si só, esse modelo não aponta balizas sobre como observar detalhadamente a produção do conteúdo da lei no parlamento. Por isso, combinada a essa proposta, Zampieri (2013) observa as ações de defesa de interesses dos grupos de pressão nas Comissões Parlamentares em três momentos decisórios: definição da relatoria, formulação do parecer do relator e definição do posicionamento da comissão. No momento da definição do relator, o autor verifica que as ações possíveis são restritas ao convencimento dos atores políticos, com o objetivo de influenciar o presidente da comissão na indicação do(a) deputado(a) cujas ideias se alinhem com as do grupo de pressão. Durante a formulação do parecer pelo relator, as ações são realizadas com mais facilidade pelos grupos, pois existe a oportunidade de apresentar seu posicionamento "sob a forma de petições, memoriais ou pareceres que são empregados junto aos deputados federais, na tentativa de adequar o texto da proposição aos interesses defendidos" (Aragão, 1994 apud Zampieri, 2013, p. 133). No momento do posicionamento da comissão, a ação do partido terá maior influência. Por isso, os grupos de pressão atuam para convencer os membros da comissão a votarem pela aprovação ou rejeição do parecer do relator, a depender de como seus interesses se adequam ou não ao texto apresentado.

A partir desses referenciais, apresentamos um quadro em que relacionamos a atuação do Consórcio nos momentos decisivos apontados por Zampieri (2013) em cada comissão. Em seguida, identificamos o repertório de ação do grupo nesses momentos e os principais resultados deliberados nas 
respectivas Comissões, a respeito do projeto de lei ${ }^{32}$. Assim, podemos ensaiar uma correlação entre os repertórios mobilizados pelo Consórcio e o suposto efeito no texto da lei ao longo da tramitação. O intuito será tratar essa tentativa de correlação como um indicativo de que movimentos sociais precisam ser mais bem observados na arena legislativa.

No quadro 2, verificamos que os principais repertórios de ação do Consórcio podem ser agrupados da seguinte forma: atuação junto a atores-chave no processo legislativo (relatoras, presidente da comissão, assessor parlamentar e ministra) e atuação nas comissões (acompanhamento de reuniões; participação em audiências públicas e seminários; participação na redação do parecer do projeto; e negociações em relação ao parecer e ao posicionamento das comissões). De forma comparada, nos parece que o Consórcio atuou de forma mais intensa junto à relatora da Comissão de Seguridade Social, cujo partido pertencia à coalizão do governo.

A própria deputada Jandira Feghali (PCdoB-RJ) reconhece o papel do grupo ao afirmar que sem a contribuição do Consórcio, conquistas importantes não teriam se efetivado na lei promulgada como, por exemplo, a não aplicação da Lei 9.099/95 (entrevista 6). Não por acaso, nessa comissão as integrantes do Consórcio foram responsáveis junto à deputada pela própria escrita do parecer, que excluiu a aplicação da Lei 9.099/95 nos casos de violência doméstica. Em síntese, o contato do grupo junto às relatoras ficou mais evidente nas comissões CSSF, CFT (Câmara dos Deputados) e CCJ (Senado). Nesses casos, a atuação do grupo se concentrou mais no momento da formulação do parecer das relatoras.

\footnotetext{
32 Como já indicamos na Introdução, as informações sobre a atuação do Consórcio nas comissões foram coletadas: a) pela "ficha de tramitação" do projeto disponível nos sites da Câmara dos Deputados e Senado Federal; b) por meio das entrevistas realizadas na pesquisa de mestrado de Carone (2017); e c) pelo material bibliográfico produzido pelas integrantes do Consórcio (Barsted, 2011; Calazans e Cortes, 2011; Lavigne, 2011). A informação sobre os resultados deliberados nas comissões são extraídas dos textos aprovados em cada colegiado e também são disponibilizados na "ficha de tramitação".
} 


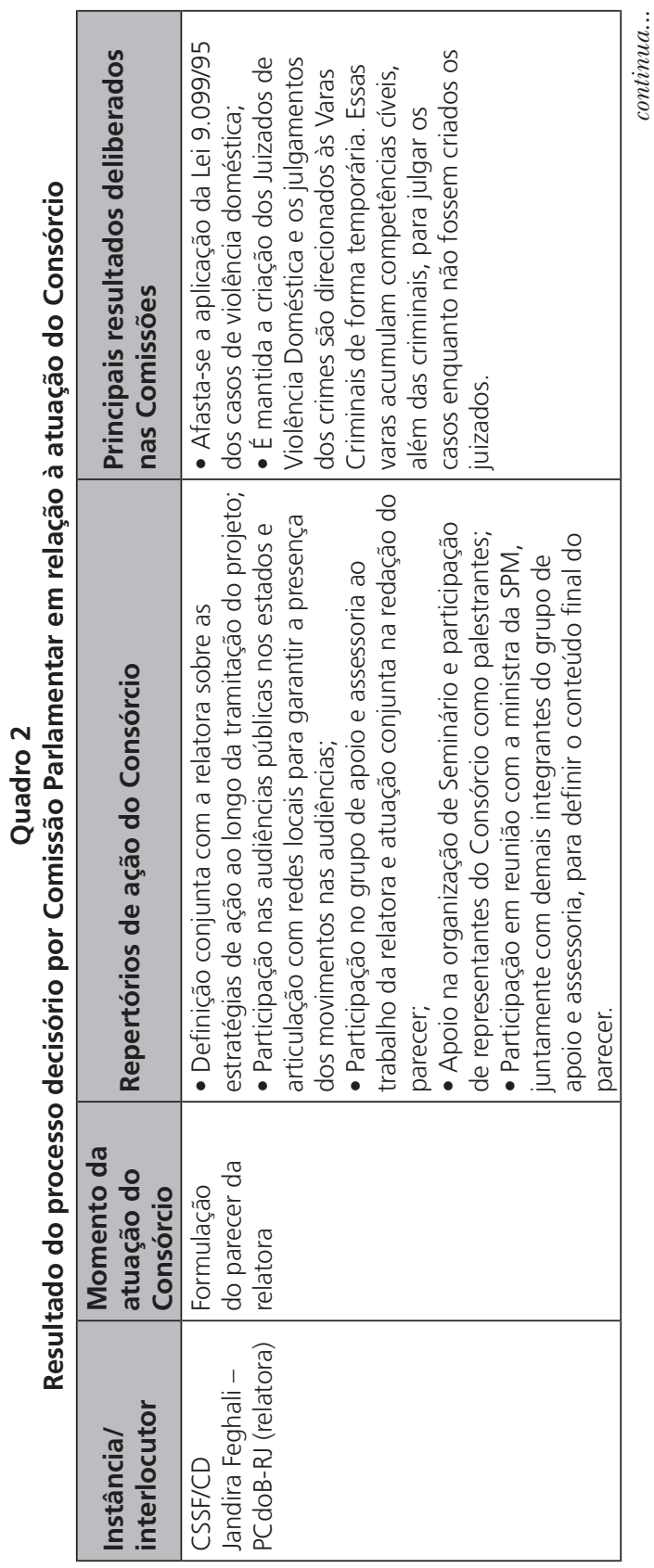




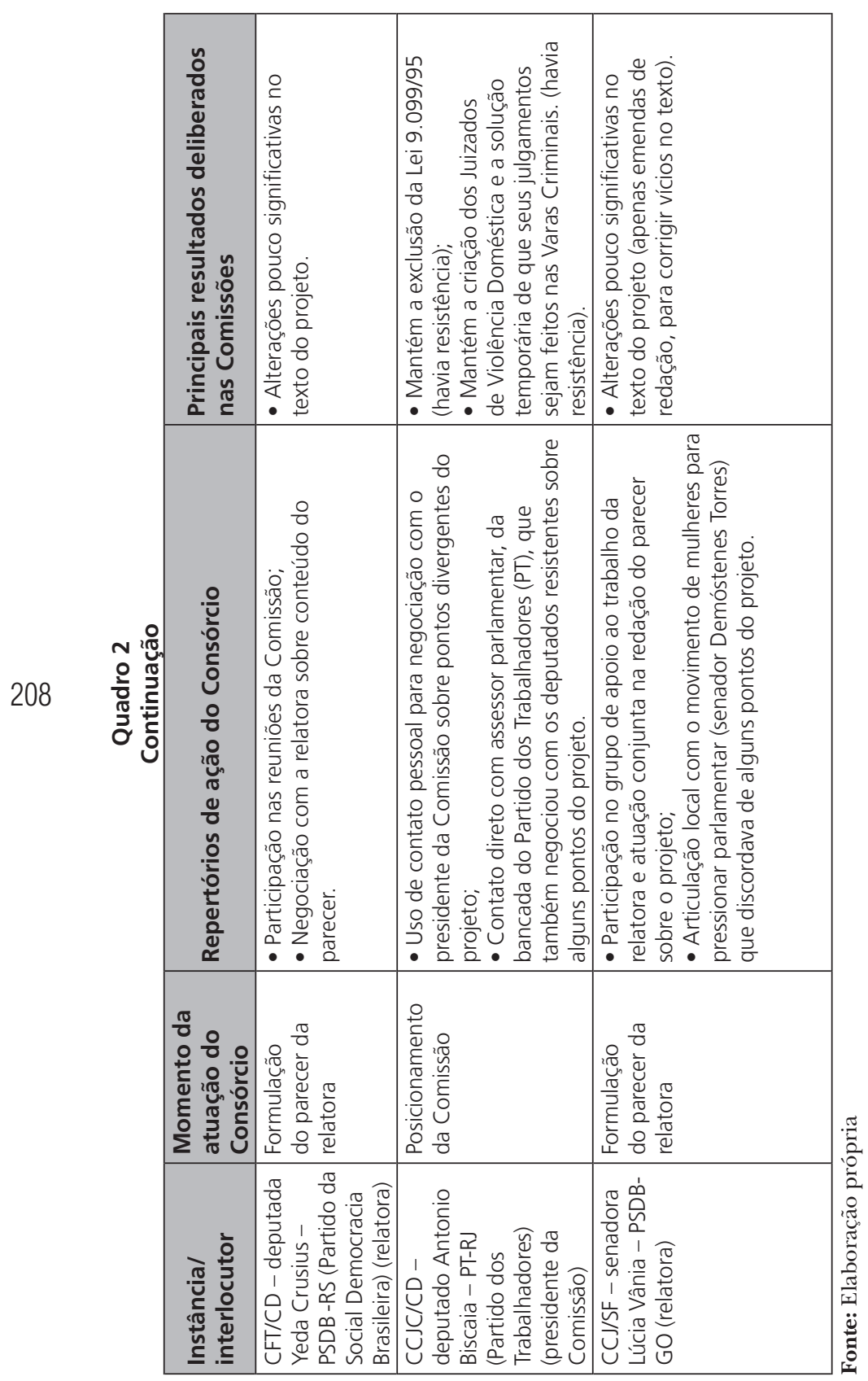


Na CGJC da Câmara dos Deputados, o grupo neutralizou posições contrárias de parlamentares em relação a pontos inegociáveis do texto, sendo que algumas dessas posições eram representadas pelo próprio presidente do colegiado. O deputado Antonio Biscaia (PT-RJ) tinha resistência à exclusão da Lei 9.099/95 como foro de julgamento dos casos de violência doméstica e à acumulação de competências cíveis, pelas Varas Criminais, para julgar temporariamente esses delitos. Sendo assim, uma das integrantes do Consórcio $^{33}$, que tinha acesso ao deputado, buscou reverter essas posições e as entrevistas (4 e 7) indicam que esse fator facilitou a negociação interna das resistências na Comissão. Além disso, o Consórcio teve o apoio de um assessor parlamentar do PT, que estava envolvido com o projeto desde a sua redação. Em síntese, aqui a atuação do grupo se concentrou mais no momento da definição do posicionamento da Comissão.

A tramitação nas demais comissões manteve as alterações, favoráveis ao Consórcio, em relação aos dois pontos principais defendidos pelo grupo: a) não aplicação da Lei 9.099/95 nos casos de violência doméstica contra a mulher; e b) criação dos Juizados de Violência Doméstica e Familiar contra a mulher, com competência cível e criminal. Ao final, essas alterações constaram no texto da lei promulgada e consideramos que a atuação do Consórcio foi uma condição necessária para alcançar tal resultado.

Como já foi apontado, um projeto de lei não é aprovado sem o apoio da maioria e do Executivo, ou seja, para as alterações realizadas ao longo do processo constarem na lei foi necessário obter esse apoio. A coalizão com status majoritário tem mais chances de ser bem-sucedida nas modificações propostas, por isso, o fato de a relatora principal da matéria

${ }^{33}$ Rosane Lavigne, integrante do Consórcio, é defensora pública do estado do Rio de Janeiro. 
ter se engajado no caso, em articulação com o Executivo e demais relatoras, também contribuiu para o resultado final.

O modelo proposto por Amenta et al (2010 apud Carlos, Dowbor e Albuquerque, 2017) defende que os movimentos ganham influência política quando adaptam suas estratégias e formas organizacionais ao contexto político específico e obtêm apoiadores entre os atores estatais, como o caso aqui exposto também parece indicar. Modelos explicativos recentes sobre efeitos políticos de movimentos sociais apontam para "a necessidade de considerar as dimensões do movimento social e do estado de forma combinada" (Carlos, Dowbor e Albuquerque, 2017, p. 375). Da mesma forma, nesse caso, trata-se de um processo no qual essas diferentes dimensões operam simultaneamente. Por fim, no âmbito da atuação dos movimentos sociais, esse caso nos indica que a sua ação produziu efeitos importantes sobre a formação da agenda e o conteúdo legislativo da 210 Lei Maria da Penha.

\section{Considerações Finais}

Esta pesquisa explorou os efeitos da atuação do Consórcio feminista no caso da Lei Maria da Penha. Para entender esses efeitos, foi necessário observar os repertórios de ação do Consórcio ao longo da produção da política e sua articulação com membros do Executivo e Legislativo nas arenas institucionais. Ao elaborar um anteprojeto de lei, o Consórcio se concentrou em defender suas ideias junto aos atores políticos para inserir o tema na agenda e também para garantir que o conteúdo legislativo se alinhasse às suas principais demandas. Para tanto, suas integrantes mobilizaram uma série de repertórios que envolvem desde o conhecimento técnico sobre a temática da política pública e do processo legislativo, até contatos pessoais com atores políticos. Levando isso em conta, é importante ressaltar que a atuação dos movimentos sociais no parlamento exige uma 
série de recursos que podem limitar o seu amplo acesso a essa arena institucional.

Do ponto de vista da literatura, tanto nas pesquisas sobre movimentos sociais quanto nos estudos legislativos, sabe-se muito pouco sobre a atuação dos atores sociais no parlamento (Abers, Serafim e Tatagiba, 2014; Santos, 2014). A produção bibliográfica sobre o tema é escassa, o que influencia na produção de pesquisas mais exploratórias, como é o caso deste trabalho. Apesar disso, em termos da atuação do Consórcio sobre a Lei Maria da Penha, esse caso nos parece indicar que a sua atuação produziu efeitos importantes sobre a produção da política pública no Legislativo.

Por fim, é importante explicitar que em 2004 a pauta da violência doméstica contra a mulher chegou ao Congresso, com grandes chances de ser aprovada, vinte anos depois das primeiras manifestações do movimento feminista sobre a questão. No entanto, essa é apenas uma das pautas do movimento e questões relativas aos direitos reprodutivos, por exemplo, não parecem ter avançado da mesma forma. Em termos comparativos, reflexões sobre a permeabilidade do Estado em relação ao avanço dessas agendas seriam uma interessante contribuição para esse campo de pesquisa.

\section{Renata Rodrigues Carone}

É mestre em Ciência Política pela Universidade Estadual de Campinas (Unicamp), pesquisadora do Núcleo de Estudos em Participação, Movimentos Sociais e Ação Coletiva (Nepac) e doutoranda em Estudos de Gênero pela Universidade de Lisboa, Portugal.

\section{Bibliografia}

ABERS, Rebecca; SERAFIM, Lizandra; TATAGIBA, Luciana. 2014.

Repertórios de Interação Estado-Sociedade em um Estado

Heterogêneo: A Experiência na Era Lula. Dados, v. 57, n. 2, pp. 325-357. 
ABERS, Rebecca; TATAGIBA, Luciana. 2014. Institutional activism: mobilizing for women's health from inside the Brazilian bureaucracy. In: Encontro Anual da Associação Nacional de Pós-Graduação e Pesquisa em Ciências Sociais, 38., Caxambu, 27-30 out.

ALVES, Branca Moreira. 1980. Ideologia e feminismo: a luta da mulher pelo voto no Brasil. Petrópolis: Vozes.

AMENTA, Edwin et al. 2010. The political consequences of social movements. Annual Review of Sociology, v. 36, pp. 287-307.

ANDREWS, Kenneth T.; EDWARDS, Bob. 2004. Advocacy organizations in the U.S. political process. Annual Review of Sociology, v. 30, pp. 479-506.

BARSTED, Leila Linhares. 1994. Em busca do tempo perdido: mulher e políticas públicas no Brasil (1983-1993). Estudos Feministas, n. especial, pp.38-54.

2007. A resposta legislativa à violência contra as mulheres no Brasil. In: ALMEIDA, Suely Souza de (org.). Violência de gênero e políticas públicas. Rio de Janeiro: UFRJ, pp. 119-136.

2011. Lei Maria da Penha: uma experiência bem-sucedida de advocacy feminista. In: CAMPOS, Carmen Hein de (org.) Lei Maria da Penha: comentada em uma perspectiva jurídico feminista. Rio de Janeiro: Editora Lumens Juris, pp. 13-37.

BIROLI, Flávia. 2018. Gênero e desigualdades: limites da democracia no Brasil. 1. ed. São Paulo: Boitempo.

BLAY, Eva Alterman. 2008. Assassinato de mulheres e direitos humanos. São Paulo: Editora 34.

BOHN, Simone R. 2010. Feminismo estatal sob a presidência Lula: o caso da secretaria de política para as mulheres. Revista Debates, v. 4, n. 2, pp. 81-106.

BRANDÃO, Lucas Coelho. 2011. Os movimentos sociais e a Assembleia Nacional Constituinte de 1987-1988: entre a política institucional e a participação popular. Dissertação de Mestrado em Sociologia, São Paulo: USP.

BRASIL. 2006. Memória 2003-2006: Secretaria Especial de Políticas para as Mulheres/Presidência da República. Brasília, DF: Secretaria Especial de Políticas para as Mulheres. 2010. Lei Maria da Penha: Lei no 11.340, de 07 de agosto de 2006, que dispõe sobre mecanismos para coibir a violência doméstica e familiar contra a mulher. Brasília: Câmara dos Deputados, Edições Câmara.

2011. Regimento Interno da Câmara dos Deputados. 9. ed. Brasília, DF: Câmara dos Deputados, Edições Câmara. 
CALAZANS, Myllena; CORTES, Iáris Ramalho. 2011. O processo de criação, aprovação e implementação da Lei Maria da Penha. In: CAMPOS, Carmen Hein de (org.) Lei Maria da Penha: comentada em uma perspectiva jurídico feminista. Rio de Janeiro: Lumens Juris, pp. 39-63.

CAPELLA, Ana Cláudia Niedhardt; BRASIL, Felipe Gonçalves. 2015. Análise de políticas públicas: uma revisão da literatura sobre o papel dos subsistemas, comunidades e redes. Novos estudos, n. 101, pp. 57-76.

CARLOS, Euzeneia.; DOWBOR, Monika.; ALBUQUERQUE, Maria do Carmo Alves. 2017. Movimentos sociais e seus efeitos nas políticas públicas: balanço do debate e proposições analíticas. Civitas, v. 17, n. 2, pp. 360-378.

CARONE, Renata Rodrigues. 2017. Como o movimento feminista atua no Legislativo federal?: estudo sobre a atuação do Consórcio de ONGs feministas no caso da Lei Maria da Penha. Dissertação de Mestrado em Ciência Política. Campinas: Unicamp.

CARVALHO, Paulo Afonso Francisco de; TAGLIALEGNA, Gustavo Henrique Fideles. 2006. Atuação de grupos de pressão na tramitação do Projeto de Lei de Biossegurança. Revista de Informação Legislativa, v. 43, pp. 161-188.

COELHO, Rony. 2013. Legislação Participativa: atores, iniciativas e processo legislativo. Paper apresentado no 37ํㅡㄹ Encontro Anual da Associação Nacional de Pós-Graduação e Pesquisa em Ciências Sociais, Águas de Lindóia, 23 a 27 de outubro.

DOWBOR, Monika. 2012. A arte da institucionalização: estratégias de mobilização dos sanitaristas (1974-2006). Tese de Doutorado em Ciência Política, São Paulo: USP.

FIGUEIREDO, Argelina Maria Cheibub; LIMONGI, Fernando. 1999. Executivo e Legislativo na nova ordem constitucional. Rio de Janeiro: FGV.

FREITAS, Andréa. 2016. O presidencialismo da coalizão. Rio de Janeiro: Fundação Konrad Adenauer.

GUTIERRES, Kellen Alves. 2015. Projetos políticos, trajetórias e estratégias: a Política de Assistência Social entre o partido e o Estado. Tese de Doutorado em Ciências Sociais, Campinas: Unicamp.

HAHNER, June E. 2003. Emancipação do sexo feminino: a luta pelos direitos da mulher no Brasil, 1850-1940. Florianópolis: Mulheres; Santa Cruz do Sul: Edunisc.

JUNQUEIRA, Andréa. 2016. Desvendando o Papel da Estrutura de Comissões para a atuação da Oposição. Paper apresentado no VI Seminário Discente da Pós-Graduação em Ciência Política da USP, São Paulo, 2 a 6 de maio. 
KINGDON, John W. 1995. Agendas, Alternatives, and Public Policies. 2nd Edition. Harper Collins College Publishers. In: SARAVIA, Enrique; FERRAREZI, Elisabete. 2006. Políticas Públicas - Coletânea, v. 1. Brasília: ENAP.

LAVIGNE, Rosane M. Reis. 2011. Caso Fonaje: o ativismo de juízes integrantes do Fórum Nacional dos Juizados Especiais - Fonaje no processo de elaboração da Lei Maria da Penha. In: CAMPOS, Carmen Hein de. (org.) Lei Maria da Penha: comentada em uma perspectiva jurídico feminista. Rio de Janeiro: Editora Lumens Juris, pp.65-92.

LIN, Nelson Shih Yien. 2010. Participação popular no legislativo federal-um estudo de seus mecanismos institucionais: emendas populares no processo constituinte, iniciativa popular de lei e Comissão de Legislação Participativa. Dissertação de Mestrado em Ciência Política, São Paulo: USP.

MACIEL, Débora Alves. 2011. Ação coletiva, mobilização do direito e instituições políticas: o caso da Campanha da Lei Maria da Penha. Revista Brasileira de Ciências Sociais, v. 26, n. 77 pp. 97-112.

MATOS, Marlise. 2014. A quarta onda feminista e o campo crítico-emancipatório das diferenças no Brasil: entre a destradicionalização social e o neoconservadorismo político. Paper apresentado no $38^{\circ}$ Encontro Anual da Associação Nacional de Pós-Graduação e Pesquisa em Ciências Sociais, Caxambu, 27 a 30 de outubro.

MONTENEGRO, Marília. 2015. Lei Maria da Penha: uma análise criminológica-crítica. Rio de Janeiro: Revan.

MORAES, Aparecida F.; SORJ, Bila. 2009. Os paradoxos da expansão dos direitos das mulheres no Brasil. In: MORAES, Aparecida F.; SORJ, Bila. Gênero, violência e direitos na sociedade brasileira. Rio de Janeiro: 7 Letras, pp. 10-22.

NUNES, Maria Terezinha. 2012. Cercas que se levantam: análise das decisões do Superior Tribunal de Justiça em quatro anos de aplicação da Lei Maria da Penha. Dissertação de Mestrado em Estudos Interdisciplinares sobre Mulheres, Gênero e Feminismo, Salvador: UFBA.

PAZ, Rosangela Dias Oliveira da. 1996. Fundo Nacional de Moradia Popular. marco histórico de participação da União dos Movimentos de Moradia de São Paulo. Dissertação de Mestrado em Serviço Social, São Paulo: PUC. PEREIRA, Amanda Campanini; VASSELAI, Fabricio; SILVA, Thiago Nascimento. 2012. Vitórias e derrotas legislativas na elaboração e votação do novo Código Florestal brasileiro. Encontro da Associação Brasileira de Ciência Política, 8., Gramado, 1-4 ago.

PINHEIRO, Marina Brito. 2010. Os dilemas da inclusão de minorias no parlamento brasileiro: a atuação das frentes parlamentares e bancadas 
temáticas no congresso nacional. Dissertação de Mestrado em Ciência Política, Belo Horizonte: UFMG.

2015. Sobre a relação entre os movimentos feministas e o Estado no Brasil (2003-2014). Tese de Doutorado em Ciência Política, Belo Horizonte: UFMG.

PINTO, Celi Regina J. 2003. Uma história do feminismo no Brasil. São Paulo: Fundação Perseu Abramo.

PITANGUY, Jacqueline. 1985. Poder e autoridade: algumas questões sobre política institucional e movimentos sociais. In: Encontro Anual da Associação Nacional de Pós-Graduação e Pesquisa em Ciências Sociais, 9., Águas de São Pedro, 22-25 out.

ROMEIRO, Julieta Ferreira. 2007. A institucionalização das políticas de combate à violência conjugal no Brasil: inovações e controvérsias. Dissertação de Mestrado em Sociologia e Antropologia, Rio de Janeiro: UFRJ.

2009. A Lei Maria da Penha e os desafios da institucionalização da violência conjugal no Brasil. In: MORAES, Aparecida F.; SORJ, Bila. (org.). Gênero, violência e direitos na sociedade brasileira. Rio de Janeiro: 7 Letras, pp. 49-74.

SAFFIOTI, Heleieth I. B. 2013. A mulher na sociedade de classes: mito e realidade. 3. ed. São Paulo: Editora Expressão Popular.

SANTOS, Cecília MacDowell. 2010. Da delegacia da mulher à Lei Maria da Penha: Absorção/tradução de demandas feministas pelo Estado. Revista Crítica de Ciências Sociais, v. 89, pp. 153-170.

SANTOS, Fabiano; ALMEIDA, Acir. 2005. Teoria informacional e a seleção de relatores na Câmara dos Deputados. Dados, n. 48, pp. 693-735.

SANTOS, Manoel Leonardo. 2014. Representação de interesses na arena legislativa: os grupos de pressão na Câmara dos Deputados (19832012). Texto para Discussão (IPEA), n. 1975, pp. 7-39.

SARMENTO, Rayza. 2013. Entre tempos e tensões: O debate mediado sobre a Lei Maria da Penha (2001-2012). Dissertação de Mestrado em Ciência Política, Belo Horizonte: UFMG.

TATAGIBA, Luciana; TEIXEIRA, Ana Cláudia Chaves. 2016. Efeitos combinados dos movimentos de moradia sobre os programas habitacionais autogestionários. Revista de Sociologia Política, v. 24, n. 58, pp. 85-102.

TEIXEIRA, Ana Cláudia Chaves.; TATAGIBA, Luciana; BLIKSTAD, Karin. 2015. Movimentos sociais na implementação de programas federais: reflexões a partir do caso do MCMV-E. Paper apresentado no 39ํㅜㄴ 
A atuação do movimento feminista no legislativo federal

Encontro Anual da Associação Nacional de Pós-Graduação e Pesquisa em Ciências Sociais, Caxambu, 26 a 30 de outubro.

ZAMPIERI, Enio. 2013. Ação dos grupos de pressão no processo decisório das comissões permanentes do Congresso Nacional. E-Legis, n. 12, pp. 122-136. 


\section{○) ( )}

\section{A ATUAÇÃO DO MOVIMENTO FEMINISTA NO LEGISLATIVO FEDERAL: CASO DA LEI MARIA DA PENHA}

\section{RENATA RODRIGUES CARONE}

Resumo: Este artigo pretende explorar os efeitos da atuação do movimento feminista no Legislativo federal. Trata-se do caso de um Consórcio de ONGs feministas que atuou no Congresso Nacional para aprovar a Lei Maria da Penha. Os repertórios de ação mobilizados pelo Consórcio são descritos a partir de sua atuação no percurso legislativo do projeto na Câmara dos Deputados e no Senado Federal. Dos resultados encontrados, constatamos que o Consórcio atuou ao longo da tramitação do projeto nas Comissões Parlamentares do Legislativo federal em, pelo menos, dois momentos chave: a) formulação do parecer das relatoras e b) posicionamento das comissões. No âmbito geral, os resultados da pesquisa indicam que a atuação do Consórcio ocorreu na fase de formação da agenda e na definição do conteúdo da Lei Maria da Penha.

Palavras-chave: Movimentos sociais; Feminismo; Poder Legislativo; Lei Maria da Penha.

\section{THE ACTION OF FEMINIST MOVEMENT IN THE FEDERAL LEGISLATIVE: MARIA DA PENHA LAW CASE}

Abstract: This article aims at exploring the effects of feminist movement in the Federal Legislative. Therefore, the study focuses on a feminist NGO Consortium that has acted in the National Congress to approve Maria da Penha Law. The repertoire mobilized by the Consortium in the case is described from the logic of the legislative process both in the Chamber of Deputies and in the Federal Senate. From the results found, it is possible to state that the Consortium acted during the bill's proceedings within the Parliamentary Committees in, at least, two key moments: a) formulation of the rapporteurs' decision and 
b) definition of the Committee's position. In a broader context, the research results indicate that the movement's action occurred in the processes of agenda setting and definition of the Maria da Penha Law content.

Keywords: Social Movements; Feminism; Legislative Power; Maria da Penha Law.

Recebido: 24/07/18 Aprovado: 05/11/18 